Tesis. Año 13, 12(14), 2019, 87-104

\title{
La integración entre el arte precolombino y moderno en la xilografía de Julio Camino Sánchez
}

\author{
Javier Fernando Rodríguez Canales \\ jfrc2309@gmail.com
}

\section{Resumen}

El artículo busca establecer que uno de los principales aportes de la xilografía de Julio Camino Sánchez a la plástica peruana fue su proceso particular de integración entre el arte precolombino y lo moderno a través de la síntesis de las formas y la composición. Para ello se distingue la diferencia entre abstracción y síntesis, siendo esta última, la tendencia predominante en las obras señaladas. Después de un análisis de las xilografías, se afirma que el artista realizó un proceso de síntesis formal tomando como principal referencia el arte precolombino y el lenguaje plástico moderno. Finalmente se explica la pertinencia y los aportes de una síntesis formal que integra lo peruano y lo moderno para la plástica nacional.

Palabras clave: síntesis, abstracción, arte precolombino, xilografía.

\begin{abstract}
The article proposes that one of the main contributions of Julio Camino Sánchez's woodcut to Peruvian art, was his particular process of integration between the pre-Columbian art and the modern age through the synthesis of forms and composition. The difference between abstraction and synthesis is distinguished, being the last one the predominant tendency in this art works. After the analysis of the woodcuts, it is stated that the artist did a formal synthesis process taking references from the pre-Columbian art and the plastic modern language. Finally, the relevance and contributions of the formal synthesis that integrates the Peruvian and the modern in the xilografía of Julio Camino Sánchez for the national plastic are explained.
\end{abstract}

Keywords: synthesis, abstraction, pre-Columbian art, woodcut. 


\section{La integración entre el arte precolombino y moderno en la xilografía de Julio Camino Sánchez}

\section{Introducción}

Julio Camino Sánchez nació en la ciudad de Trujillo en 1914 y falleció en Lima en el año 2007. Pintor, grabador y escenógrafo, cultivó desde muy joven la técnica de la xilografía; disciplina en la cual llegó a un alto grado de maestría ${ }^{1}$, la cual fue reconocida en su momento por críticos como Juan Manuel Ugarte Eléspuru ${ }^{2}$ y Eduardo Moll: "en nuestro medio, el grabado tiene pocos adeptos, desgraciadamente. Uno de ellos es un excelente especialista en la xilografía o grabado en madera. Nos referimos a Julio Camino Sánchez, quien hace poco ha lanzado una colección de once láminas de colores, magníficamente elaboradas dentro de un fino espíritu abstracto" ${ }^{3}$.

Si bien el artista trujillano se desempeñó competentemente en la pintura al óleo, fue en la xilografía donde desarrolló sus propuestas más innovadoras; de esta manera, Camino Sánchez formó parte del grupo de creativos que "alcanzaron las cotas más altas de su producción en esta disciplina, aun cuando ellos eran considerados prioritariamente como pintores" (Munive, 2015, p. 14). La preferencia de muchos artistas del siglo XX por la xilografía se debió a la facilidad de la técnica, los bajos costos de implementación y sus posibilidades expresivas, porque "en sus aspectos formales se aprecia, como elementos distintivos de creación, la huella que deja la cuchilla o gubia del grabador en ritmos constantes o sea que aparece la técnica del corte utilizado y su cadencia como elemento de dibujo" (Fernández, 1995, p. 52).

Las participaciones del maestro trujillano en muestras, concursos y bienales de grabado fueron abundantes, entre las cuales destacan la Cuarta Bienal Internacional de Tokyo (1964), la VII bienal de Sao Paulo (1965), el Salón internacional del Grabado de Estocolmo (1965), la Exposición Internacional de Xilografía Contemporánea América- Europa- Oriente, del Museo Español 
de Arte Contemporáneo de Madrid (1972) y la muestra en la Galería AGO de Berlín (1978).

Gracias a la xilografía, Camino Sánchez obtuvo premios significativos como el tercer lugar de grabado en la Exposición Internacional de Bellas Artes en Valparaíso (1939), el tercer premio del Salón Nacional de Grabado del Instituto Cultural Peruano Norteamericano (ICPNA) de 1967 y el primer premio del mismo salón en el año 1968 con la obra titulada Batán Chico (Figura 1).

Se aprecia en las xilografías de Camino Sánchez, una inquietud por investigar diferentes estilos artísticos locales y extranjeros, haciendo un esfuerzo de integración en el cual se empeñó a lo largo de toda su carrera. En una entrevista aparecida el 3 de agosto de 2005 en el diario La República, el artista declaró lo siguiente: "He experimentado con todas las técnicas y con todas las corrientes: el indigenismo de Sabogal, el de Vinatea Reynoso, el cubismo. En el grabado me inspiré en la escuela mexicana. También he incursionado en el pop art y la abstracción"4.

Es a partir de una mirada amplia que ensayamos un ordenamiento de la obra xilográfica en cuatro vertientes estilísticas, las cuales hemos denominado como: indigenista $(1934-1963)^{5}$, popular (1963-1970), precolombina (19461969) y experimental (1946-1968) .

Las obras de corte indigenista son las más antiguas y se caracterizan por retratar al hombre y el paisaje rural con la intención de valorarlos. Las primeras xilografías aparecen el año 1934, abarcando las décadas de los cuarenta, los cincuenta e inicios de los sesenta. Dentro de este grupo se perciben dos expresiones particulares; una peruana y otra mexicana. La primera, que fue realizada en las décadas de los treinta y cuarenta, tiene influencias de José Sabogal y su grupo (Figura 2). La segunda expresión, que fue desarrollada en las décadas de los cincuenta y sesenta, representa personajes populares estilizados y está inspirada en la serie Niños mexicanos de Diego Rivera (Figuras 3)7.

Con respecto a las obras inspiradas en el arte popular, recordamos que nuestro artista participó del proyecto de documentación y rescate del arte popular peruano impulsado por José Sabogal a través del Instituto de Arte Peruano (1931-1973) que fue parte del Museo de la Cultura Peruana ${ }^{8}$. El arte popular peruano, nacido del mestizaje entre el elemento indígena e hispano, es el producto de un largo proceso histórico en el cual se fueron incorporando temas y formas provenientes de la vida campesina. El mestizaje no tuvo una retórica de ruptura sino de recomposición que según Sabogal, se manifestó particularmente en el mate y el quero:

Al trabajo gráfico sobre los mates se sumó el de los queros, un objeto ceremonial cuya morfología se remonta en su forma al periodo Tiahua- 
naco, y la madera, su materia prima, es un aporte de los Incas. En consecuencia, tanto por la originalidad de su forma, como por su naturaleza histórica, cumplía con la propuesta de arte mestizo. (Villegas, 2017, p. 15)

Camino Sánchez elaboró diversas carpetas que contenían series de xilografías dedicadas al arte popular, destacando entre ellas las carpetas de la Imaginería de Ayacucho (1963), las Máscaras de Danzas (1964), el Mate Burilado (1965) y el Toro de Pucará (1970). En dicho trabajo, no se percibe necesariamente una intención de especulación formal, sino una labor de documentación estética. Las obras dedicadas al arte popular peruano son de suma importancia porque en ellas se ve el concepto de mestizaje que va a consolidar la idea de peruanidad del artista.

La vertiente que revela el estudio meticuloso que hizo Camino Sánchez del arte precolombino está conformada por un grupo considerable de obras que reproducen motivos del arte Chavín (Figura 4), las líneas de Nazca y la cerámica Moche. El interés del artista no solo estuvo en el arte proveniente de las culturas señaladas, sino que también prestó especial atención al arte rupestre. Entre las obras más emblemáticas que hacen referencia a dicho arte, se encuentra una que tiene un personaje hierático (Figura 5) que representa un chamán muy similar al que aparece en los petroglifos hallados en sitio denominado EH1 del valle de Chicama (Figura 6); también se perciben similitudes entre las formas aglomeradas de Toro Muerto (Figura 7) con las contenidas en xilografías de la década de 1960 (Figura 8).

Las obras de corte experimental son un conjunto de xilografías que contienen diseños y composiciones que no tienen la intención de documentar un arte determinado, tal como sucede con las carpetas de arte popular, si no, de elaborar combinaciones de diferentes elementos provenientes del arte precolombino y del arte moderno. Dentro de esta vertiente se identifican dos etapas: una primera conformada por una serie de seis obras del año 1946, que no tienen título, cinco de las cuales son esferas que contienen formas sintetizadas y una que representa la cabeza de un pez. La segunda etapa es del año 1969, en la cual el artista ha incorporado más elementos del arte moderno utilizando tacos del año 1946. La mayoría de estas obras están agrupadas en la carpeta titulada Operación Ayar, que es donde el artista presenta su propuesta más acabada por la integración armoniosa de composiciones geométricas modernas, fondos que revelan la textura de la madera y formas provenientes del mundo precolombino.

Si observamos las fechas en que han aparecido las cuatro vertientes que hemos señalado, podemos decir que hubo continuidad entre las etapas indigenista y popular, mientras que las vertientes precolombina y experimental fueron desarrolladas casi en el mismo periodo de tiempo. Siendo que el indigenismo 
y el arte popular estaban conectados por la reflexión acerca de la construcción de un arte con identidad peruana y que el final de la primera vertiente coincide con el inicio de la segunda, se percibe un desarrollo lineal orientado hacia la búsqueda de un arte nacional mestizo. Ambas vertientes (indigenista y popular) son figurativas y no tienen señales significativas de síntesis formal, por ello, no nos ocuparemos de ellas en el presente artículo.

Con respecto a la relación entre la vertiente precolombina y experimental, se destaca que prácticamente son simultáneas, que ambas manifiestan formas construidas a modo de síntesis y que la vertiente experimental tiene muchos referentes precolombinos integrados con elementos del arte moderno como la composición y el diseño. Pensamos que la principal motivación de nuestro artista, quien afirmaba que "nuestro país tiene una historia muy valiosa, la labor de las culturas aborígenes y el enriquecimiento de la yuxtaposición de lo occidental", estuvo en la necesidad de armonizar lo moderno con las propias raíces, porque como dice Munive (2018): "al familiarizarnos con nuestros repertorios iconográficos precolombinos contribuiremos con su valoración como patrimonio cultural y daremos a las artes visuales peruanas una razón indudable parar prolongar hacia el pasado las raíces de su contemporaneidad".

Camino Sánchez no fue el único, ni el primero en ensayar una síntesis del arte precolombino en diálogo con lo moderno, esta inquietud tuvo antecedentes en el trabajo de artistas egresados de la ENBA que ilustraron piezas arqueológicas, sobresaliendo entre ellos, Elena Izcue, quien estudió el arte del Perú Antiguo con la intención de generar diseños modernos y Alejandro Gonzales Trujillo "Apurimak", que habiendo sido dibujante del Museo Arqueológico, que en ese momento estaba bajo la dirección de Julio C. Tello, "se mantuvo actualizado en términos de modernidad y trabajó al margen de la ortodoxia indigenista" (Morris, 1981).

Una de las influencias de la obra de Izcue en nuestro artista se evidencia en la elaboración de materiales para el aprendizaje del dibujo precolombino ${ }^{10}$, pero además, la comparación de los diseños de Izcue y de Camino Sánchez arroja un proceso similar de síntesis de formas con una intención modernizadora. Así como en la obra de Izcue "esta propensión hacia la síntesis y hacia la selección de motivos puntuales, refleja el propósito de aislar elementos que pudieran emplearse como pretextos ornamentales para los objetivos decorativos que por entonces empezaba a crear" (Majluf y Wuffarden, 1999, p. 53), en las xilografías experimentales de Camino Sánchez se ven fragmentos de diseños Chavín (volutas de la Estela Raimondi en la Figura 1), Tiahuanaco (dios de los báculos o Huiracocha) (Figura 9), Chimú (Pelícano sintetizado en ceramios y tejidos) y del arte rupestre peruano ${ }^{11}$, sirviendo todo ellos para la construcción de patrones que constituyen el contenido de una forma nueva. 
Si bien existen similitudes y evidentes influencias, se perciben diferencias en los medios técnicos y en las especulaciones posteriores. Con respecto a la técnica, mientras Elena Izcue se enfocó en la producción de acuarelas, telas pintadas y collage, Camino Sánchez se orientó hacia la xilografía y la pintura mural. En cuanto a las especulaciones, la artista limeña acentuó la textura y el tramado regular (Figura 10), por otro lado, el artista trujillano se concentró en la composición de formas, las cuales ciertamente contienen un tramado, pero irregular (Figura 11). A pesar de algunas diferencias, podemos decir que ambos creativos no hicieron una simple reproducción de los elementos precolombinos, sino que elaboraron nuevas imágenes desde el espíritu moderno.

Un ejemplo del espíritu especulativo de nuestro artista lo encontramos en la polémica en torno a una exposición donde exhibió los tacos originales que usó para sus xilografías "experimentales" en la Librería Galería Quartier Latin en marzo de 1968 (Figura 12), "referente a esto, Camino tuvo hace poco una idea que consideró buena. En lugar de sacar copias en papel, unir todos los tacos y exponerlos como originales. Lo hizo y hubo muchas discusiones"12. Algunos interpretaron la propuesta como un mero juego estético: "Camino Sánchez ha querido ahora, lo que es perfectamente comprensible, renovarse; pero ello no lo ha hecho sino desde un aspecto puramente formal. Al utilizar los tacos originales del grabado en lugar de este mismo, ha conseguido agradables resultados de pintoresco colorido... es todo lo que podemos mencionar. Otra novedad no hay. Pero los artistas pueden a veces intentar algunas travesuras y volver al buen sendero"13. No faltaron aquellos que con ocasión de la muestra reflexionaron acerca de temas artísticos fundamentales: "En cierto modo se trata de cambiar la categoría artesanal (que algunos adjudican al grabado, pero no este cronista ciertamente) por la jerarquía de obra artística. Pero considerar al grabado artesanía es discutible y la distinción entre artes mayores y menores tiene cada día menos partidarios"14. Finalmente, también hubo críticas formales y técnicas que enriquecieron la polémica: "Camino Sánchez da un paso regresivo: los tacos pierden su realidad de medios para convertirse en relieves coloreados, cuyas ornamentaciones son de inspiración primitivista y abarrocada. Al parecer, la madera repele al color y al barroquismo. Su riqueza texturológica se pierde"15.

Es importante destacar que, a pesar de las críticas, Camino Sánchez continuó trabajando la temática con la que ganaría algunos meses después el IV Salón de Grabado del ICPNA, el cual se destacó, según la prensa de la época, por la calidad y la modernidad de las obras presentadas: "La muestra conjunta presenta un panorama del actual grabado con realizaciones que abracan las más diversas escuelas y tendencias, desde el grabado figurativo hasta atrevidas realizaciones vanguardistas" ${ }^{16}$. Dentro del conjunto, se pone de relieve que Julio Camino Sánchez es "un artista de méritos sobresalientes y de largo trabajo serio y responsable. Dentro del género reproductivo con técnicas a la xilografía y la 
litografía ha logrado un cúmulo de obras de verdadera calidad y de singulares méritos estéticos" ${ }^{* 17}$.

\section{Abstracción, síntesis y composición moderna}

El trabajo de nuestro artista está compuesto por xilografías que requieren en primer lugar de algunas reflexiones acerca de la abstracción, la síntesis y la composición moderna.

Abstraer (Abstráhere en latín), significa alejar o separa. En el caso del arte abstracto se entiende como el proceso por el cual se producen imágenes alejadas de la realidad aparente: "Como todo el mundo sabe, el proceso de abstracción es la operación intelectual por la cual aislamos de los objetos físicos o de los actos concretos ciertas cualidades" (Miró Quezada, 1966, p. 161).

El proceso de abstracción es connatural al ser humano, por ello siempre estuvo presente en la historia del arte. Para Fernández (2003) "la voluntad de abstracción se halla ínsita en la mente y la cultura humanas, desde los tiempos más antiguos del Paleolítico" (p. 11). Según Juan Eduardo Cirlot, es posible identificar en la abstracción de la antigüedad dos principios casi opuestos y al mismo tiempo complementarios:

Esos dos principios esenciales son: la forma primitiva producida por el gesto motor, la maraña lineal, el ritmo discontinuo [...] y la trama geométrica, la forma regular plana, realizada no con criterio representativo sino como directa imposición de unos elementos de orden y simbolización del espacio y de los valores esenciales. (Cirlot, 1965, pp. 13-14)

Sin embargo, a pesar de la tendencia natural hacia abstracción que puede llevar a que algunos autores afirmen que "todo el arte indígena americano ha sido esencialmente abstracto, tanto en la escultura de Chavín, como de Tiahuanacu" (Fernández, 2003, p. 11), señalamos que la abstracción en el arte tiene características particulares de acuerdo al tiempo y el lugar en que el artista lo realiza. Si consideramos que el acto de abstraer separando la imagen de la realidad procede de una mentalidad e incluso de una epistemología particular, no parece del todo acertado equiparar absolutamente el arte no figurativo del Perú Antiguo con el arte abstracto del siglo XX o de cualquier otro momento de la historia.

La abstracción antes de la modernidad, no pasaba por un ejercicio intelectual consciente sino por un impulso interior emocional y espontáneo: "La capacidad de abstracción que tiene el hombre fue figurativa antes que intelectiva: la historia del abstracto, pues se remonta al Paleolítico" (Castrillón, 2002, p. 16). Por otro lado, la abstracción moderna es aquella tendencia artística nacida en 
occidente, influenciada por la ilustración que promovió la exaltación del yo, de la razón y de la subjetividad, alcanzando su expresión más representativa en el siglo XX.

Castrillón (2002), atribuye el nacimiento inmediato del arte abstracto moderno a la reacción ante el horror de la primera guerra mundial:

Lo que pasó entonces en Europa no se lo había imaginado ninguna mente apocalíptica; fue el comienzo de una gran tragedia que sembró hambre, terror y muerte. Así como las bombas destruyeron el paisaje bucólico de Europa, los artistas quisieron desaparecer la naturaleza de sus cuadros; avergonzados y llenos de temor borraron su imagen. La relación armoniosa y confiada del hombre con su mundo exterior había desaparecido. Frente a este escenario se comprende el paso de la figuración al abstracto en la cultura europea. (p. 18)

Si bien la primera guerra mundial fue un acontecimiento lo suficientemente poderoso como para generar un cambio artístico significativo, además pensamos que existen otras causas previas que pudieron contribuir en la consolidación de una tendencia hacia la subjetividad con el consecuente abandono de la representación de la realidad. Nos referimos al pensamiento estético de Kant y a la búsqueda por parte de los artistas de un lenguaje que estuviera en sintonía con dicho espíritu moderno.

El pensamiento estético general, pero particularmente el de Kant, se construyó desde la subjetividad. Kogan (1986), comentando a Kant, nos dice que "la belleza no se reduce a una aprehensión sensorial ni es defendible por medio de conceptos. Calificamos como bella una imagen que nos produce un sentimiento de placer, esto es, algo subjetivo" (p. 250). La subjetividad no es solamente punto de llegada de la experiencia visual sino también el punto de partida desde una idea preconcebida, "el artista, según Kant, parte siempre de un concepto de lo que va a hacer, pero transforma el objeto pensado en una idea infinita, que ningún pensamiento ya no es capaz de traducir" (Kogan, 1986, p. 257). Este mismo espíritu moderno será recogido posteriormente por los artistas del grupo peruano Espacio: "En nuestros días los pintores se hallan empeñados, similarmente, en sentar las bases de un lenguaje pictórico dirigido ya no a la representación del mundo sino al descubrimiento de los valores propios del hecho plástico" (Miró Quezada, 1966, p. 163). En resumen, podemos decir que la idea de liberación de la realidad negando su representación para alcanzar los valores puros del arte, es una de las características más importantes del espíritu abstracto moderno.

La abstracción en el mundo precolombino no respondió al mismo espíritu de la modernidad. Es más preciso decir que en dicho arte hubo un proceso de síntesis. Mientras que la abstracción moderna buscó la separación de la reali- 
dad, "la síntesis es una operación cuya esencia consiste en recomponer un todo a partir de sus elementos constitutivos. $\mathrm{O}$ sea, se trata de un proceso inverso al analítico" (Fernández, 2003, p. 466). En ese sentido, entendemos la síntesis como un proceso de recomposición a través de la producción de formas simplificadas. La abstracción moderna también simplificó y sintetizó, pero con la intención de abandonar la representación de la realidad y afirmar los valores plásticos en sí mismos, mientras que el arte precolombino simplificó y sintetizó las formas para comunicar ideas.

Ruiz Durand (2004), al señalar el carácter comunicativo del arte del Perú Antiguo, afirma la tendencia del artista precolombino a la creación de formas simbólicas simples a través de un ejercicio de síntesis: "un lenguaje es un sistema articulado de comunicación que utiliza elementos organizados y estructurados en un código, en este caso, los elementos son iconos, signos y símbolos articulados, codificados en un vocabulario visual" (p. 20).

El arte del Perú Antiguo se ha ocupado en dos grandes temas: lo sagrado y lo profano, mientras el arte sagrado se orientó hacia la simplificación de las formas para comunicar ideas religiosas, el arte profano se caracterizó por una tendencia decorativa. Para Campana (1995), en el arte religioso Chavín: "hay signos indicadores de sacralidad y otros de divinidad" (p. 26), es así que el artista Chavín sintetiza las formas del felino, la serpiente y el halcón, animales que identifican a los dioses a través del retrato, la convención y el símbolo. Por otro lado, las obras de arte profano Chavín: "tienden hacia una abstracción decorativa, pues cada superficie lograda carece de referentes que nos pueda informar de dónde se copió o imitó tan singulares superficies porque éstas se convierten en el tema artístico mismo" (Campana, 1995, p. 144).

A partir de lo dicho, definimos que la síntesis precolombina es el proceso de simplificación de los elementos observados en la naturaleza andina y de elaboración de nuevas composiciones con la intención de comunicar ideas o decorar objetos utilitarios. En algunos casos se observa que la simplificación llegó a niveles muy elementales de formas en las cuales difícilmente se puede reconocer la figura de origen.

Una vez recogidas algunas características de la abstracción moderna y puestas en contraste con la estética precolombina, señalamos que la síntesis formal de nuestro artista es el acto de composición de una imagen a partir de formas observadas en la naturaleza que han sido simplificadas tomando como referencia la iconografía del arte peruano, particularmente del arte precolombino. 


\section{Algunas obras representativas de la xilografía de Julio Camino Sánchez}

Artista cuajado, sus xilografías se distinguen por una técnica precisa y una sugestiva línea expresiva. En las concepciones de Camino Sánchez se percibe una sobria emoción poética, una elegancia viril que recoge sus temas con simplicidad de medios al mismo tiempo que con variedad formal y cromática. El pasado prehispánico le proporciona abundantes motivos a su inspiración y él los maneja con cuidadoso sentimiento. Agallpampa, Huarnchai, Sitabamba, Suchin, son algunos de sus títulos que atraen por el modernismo de su tratamiento" ${ }^{18}$.

Para el análisis de la xilografía de Camino Sánchez hemos escogido un conjunto de obras que podrían ser representativas de la integración lo precolombino con lo moderno a través de la síntesis formal. Para el análisis se hará una descripción formal de las obras, destacando las influencias del arte peruano y moderno en la composición y los diseños, luego se realizará una descripción de la iconografía señalando los diversos referentes. Es posible que en varios casos las comparaciones de los aspectos formales e iconográficos sea en simultáneo.

Dentro del grupo de obras experimentales, destaca una xilografía sin título (Figura 11) del año 1946. La obra representa una esfera, en cuyo interior se aprecia un conjunto de formas separadas unas de otras por una trama irregular, algunas de ellas recuerdan el decorado del arte precolombino y otras formas dentadas que hacen referencia al arte rupestre. La aglomeración de los elementos es relativamente uniforme, no destacando alguna figura principal y sugiere una intención ornamental según la clasificación del arte rupestre del sur andino realizada por Rainer Hostnig ${ }^{19}$. Las formas son geométricas, no se distingue la representación de hombre alguno. Se perciben figuras de vegetales y animales tan sintetizadas que han sido reducidas a su expresión geométrica más simple. En la figura no se nota una intención directamente representativa, sino la síntesis de un conjunto de elementos enmarcados en una esfera. Una posible explicación a esta imagen la podemos encontrar en un boceto del artista donde esferas similares han sido relacionadas con los planetas (Figura 13). Otro referente es una obra de Elena Izcue, realizada entre los años 1926 y 1936, con técnica mixta sobre papel y que representa una esfera, más concretamente un sol que contiene en su interior un tramado geométrico (Figura XX).

La obra titulada Vindivil (Figura 8) (1967) actualmente forma parte de la colección permanente del Museo de Arte Moderno de Nueva York. Es una xilografía no figurativa, la silueta es semejante a la de un mate cuya parte superior es más reducida que la inferior. La obra, realizada en blanco y negro, está dividida en varias secciones horizontales. En la sección superior se perciben diseños geométricos relacionados con el dibujo arquitectónico y otras formas irregulares que recuerdan el arte precolombino. Luego de una comparación con 
los diseños Moche, Chavín y Nazca, no se han encontrado similitudes evidentes, más bien se distinguen en las secciones inferiores otras formas ovaladas que evocan elementos orgánicos provenientes del arte rupestre (Figura 7).

La tercera obra que será objeto de nuestro análisis, se titula Batán Chico (figura 1) y es una xilografía con la cual nuestro artista ganó el primero premio del salón de grabado del ICPNA en el año 1968. La composición es simple, puesto que se trata de una esfera sobre un fondo amarillo, sin embargo, en el interior de la circunferencia se perciben formas muy complejas. A diferencia de Vindivil (Figura 8), en Batán Chico se distinguen con claridad algunos referentes de las culturas precolombinas como las volutas del arte Chavín (en la parte inferior de la esfera) y formas geométricas que sugieren los frisos de la cultura Chimú (parte media y superior). También se ven formas ovaladas que recuerdan elementos orgánicos relacionados con el arte rupestre.

Operación Ayar 4 (Figura 5), está fechada en 1969. En esta xilografía se ven tres esferas, dos grandes y una muy pequeña. Las esferas grandes están colocadas de la siguiente manera: una en la parte superior y otra en la inferior, tocándose ligeramente por el borde y sugieren la forma de un ocho. En la circunferencia inferior encontramos la cabeza estilizada de un animal que nos recuerda al perro peruano, el cual ha sido hallado en diversos entierros precolombinos del norte del país. La figura tiene un decorado con formas geométricas. El perro, muy similar al Perro semihundido de Goya, parece ladrar o aullar a la luna y tiene similitudes con la obra de Rufino Tamayo, quien por lo menos pintó tres versiones del Perro ladrando la luna. Para el artista mexicano, el perro simboliza la irracionalidad del ser humano que generó el drama de la Segunda Guerra Mundial: "Yo expresé mi sentir con los perros: los perros ladrando la luna, los perros rabiosos, los perros entre la carroña, los perros amenazantes. Es decir, yo no pinté soldados ni batallas, expresé mi rabia por medio del perro" (Ávila, 2010, p. 28).

La tercera esfera (considerablemente más pequeña), se encuentra pegada al lado inferior derecho de la esfera superior y representa un astro que podría ser la luna. En la circunferencia que se halla en la parte más elevada de la composición vemos un personaje en posición hierática pero carente de indumentaria, en el interior de la figura hay diversas formas con patrones geométricos precolombinos y otros relacionados con las iniciales del autor ${ }^{20}$. Las manos carecen de dedos, mientras que los pies tienen tres dedos cada uno. El rostro no denota ira ni miedo, sino una expresión de inmovilidad o éxtasis. La posición del cuerpo es muy similar a los chamanes representados en el arte rupestre del valle de Chicama (Figura 6).

La composición de Operación Ayar 4 que nos manifiesta un animal que levanta la cabeza hacia la luna y un chamán que mira de forma hierática señala la 
tensión entre dos mundos, el natural caracterizado por la animalidad y el espiritual simbolizado por el chamán. La xilografía analizada, al contener elementos del arte precolombino y referencias al arte de Rufino Tamayo (especialmente aquel relacionado con la Segunda Guerra Mundial), es una clara muestra de un arte peruano en diálogo con las inquietudes del hombre moderno.

\section{Aportes para el arte peruano.}

Se descubre en la xilografía de Julio Camino Sánchez una confluencia de formas y estilos diferentes que indica que el artista tuvo dos grandes líneas de trabajo: la peruanidad y la modernidad.

En las vertientes precolombina y experimental no se nota ni un abandono de la peruanidad ni un rechazo de la modernidad occidental, sino un trabajo de síntesis formal y un ensayo de modernización de lo peruano. Con respecto al proceso de síntesis, el estudio de los diseños, motivos y composiciones, arroja que el artista recogió formas de la realidad para luego simplificarlas utilizando referentes del arte precolombino. Este esfuerzo de síntesis de formas precolombinas en diálogo con la modernidad tiene como uno de sus antecedentes más importantes el trabajo de Elena Izcue, quien elaboró un rico universo de imágenes con diversas aplicaciones como por ejemplo la de "adaptar el diseño precolombino para su uso en accesorios y muebles" (Villegas, 2017, p. 45).

Pensamos que la intención de síntesis del artista, proviene de una tendencia hacia la integración de la realidad que constituye una fuente significativa de su creatividad. Se aprecia en las obras de la vertiente experimental, la construcción de un universo creativo que proviene de un movimiento de contracción a través de formas simplificadas que luego serán reutilizadas en un dinamismo de expansión de imágenes, añadiendo a todo esto una nueva complejidad.

Este proceso denota una creatividad y una estética motivada por una cosmovisión, la cual se percibe en la manera en que el artista trabajó los temas del hombre, el mundo, los astros, los animales, las plantas y los seres sagrados precolombinos (Figura 4). A esto se debe añadir que en nuestra investigación hemos encontrado muestras de interés por la astronomía en sus bocetos de planetas (Figura 13) que luego aparecerán en xilografías posteriores y en los proyectos que lideró en su labor como docente ${ }^{21}$.

Una cosmovisión implica un esfuerzo de simplificación de la realidad, un posterior ordenamiento del universo y la construcción de un nuevo mundo de imágenes en consonancia con una larga tradición donde se han integrado los aportes del arte peruano y del arte occidental. 
En la obra de Julio Camino Sánchez se perciben aportes significativos como un peruanismo que integra las diferentes expresiones plásticas que han aparecido en nuestro país, revelando una continuidad histórica constructiva que no niega ni rechaza las culturas que se han encontrado en el Perú, sino que las profundiza y las integra.

Proponemos que el peruanismo de nuestro artista significa un aporte porque ante la globalización que todo lo uniformiza, consideramos que el arte es realizado por un sujeto situado en un lugar y tiempo determinados, que tiene influencias directas y por ello, son necesarias las referencias a la tradición local para proyectarse hacia el mundo.

Por otro lado, la opción del artista por priorizar el trabajo plástico a través de la síntesis de formas, es un aporte significativo porque libera al arte de las especulaciones que lo distorsionan y ofrece ángulos de la realidad que muchas veces escapan a la perspectiva racional. Cuando Camino Sánchez declaró su rechazo por la política ${ }^{22}$, estaba dando su posición acerca de la ideología que la inspira y la necesaria independencia del arte, en ese sentido, podemos decir que nuestro artista fue "un pintor independiente, enamorado de su realidad, a la cual describe con vocabulario propio y singular" (Ugarte, 1979).

Otro aporte relevante es que la xilografía investigada contiene una cosmovisión. La selección, síntesis y simplificación de formas que luego son recompuestas en nuevas imágenes, hablan de una reflexión profunda desde la cual son incorporadas las múltiples influencias que se pueden recibir. La xilografía investigada no contiene una ideología ${ }^{23}$ sino una cosmovisión alimentada con una perspectiva de síntesis.

En resumen, la xilografía de Julio Camino Sánchez nos lleva a pensar que la construcción de un arte peruano no pasa por la simple recolección de estilos del pasado, ni por hacer combinaciones novedosas, ya que todo ello no lleva más que al eclecticismo. Ante la globalización, un sistema de mercado que todo lo transforma en consumo y un arte posmoderno que se ha convertido en espectáculo, se hace necesario que el artista sea capaz de hacer una síntesis a partir de una concepción propia y bien fundamentada de la relación entre el hombre y el mundo. En esto es necesario anotar que, hoy más que nunca, una propuesta que se ocupa del Perú y sus raíces culturales profundas, es un aporte indudable para el futuro de nuestro arte. 


\section{Notas}

1 Luego de su primera exposición realizada en su ciudad natal el año 1934, ganó una beca que le permitió estudiar entre 1936 y 1942 en la Escuela Nacional de Bellas Artes, que en ese tiempo estaba bajo la dirección de José Sabogal. Desde entonces, Camino Sánchez realizó a lo largo de más de sesenta y cinco años de actividad artística cerca de setenta exposiciones individuales, siendo la última en vida, la muestra antológica organizada por la Municipalidad de Miraflores en el año 2005. Póstumamente la Galería Delbarrio de Chorrillos ha organizado muestras dedicadas a su xilografía en los años 2016 y 2017 en las ciudades de Lima, Cusco y Arequipa.

2 Ugarte Eléspuru comenta la larga trayectoria y la calidad como grabador del artista en las presentaciones de las carpetas "Arte del Perú" (1963), "El Mate Burilado" (1965) y "Paisajes Costeños" (1979).

3 Moll, 1968, p. 11.

4 Las facetas, 2005, p. 7.

5 Si bien el artista se inclinó hacia el peruanismo (postura que afirmaba que la identidad nacional se encontraba en el mestizaje), se ha elegido la palabra "indigenismo" para hablar sobre aquellas obras similares a dicho estilo artístico.

6 Hemos denominado "experimental" a un conjunto de xilografías en las cuales Camino Sánchez ha combinado elementos provenientes del arte precolombino y del moderno.

7 En el archivo personal del artista encontramos imágenes de algunas obras de Diego Rivera aparecidas en la revista "Artes de México" del año 1959, que fueron cuadriculadas con la evidente intención de hacer copias a mano que sirvieran para trabajos posteriores. Las obras indigenistas de la década de los cincuenta y sesenta provienen indudablemente de dicha referencia mexicana.

8 Una muestra de la activa participación del artista en el proyecto de documentación del arte popular realizado a través del Instituto de Arte Peruano, la encontramos en los dos cuadros de gran formato que hizo inspirado en los mates burilados y que se encuentran en la recepción del Museo de la Cultura Peruana (Figura 6) (Villegas, s/f, p. 45).

9 Exposición, 1964, p. 3.

10 Los dos artistas tuvieron en común una vocación peruanista, la actividad artística y la docencia. Siendo que Elena Izcue publicó sus dos volúmenes de "El arte peruano en la escuela" en París en 1926, es posible que haya influenciado a Camino Sánchez en la publicación de sus "Cuadernos de Dibujo de Arte Mochica y Chimú" en Lima, en el año 1944, dichos cuadernos fueron comentados con mucho entusiasmo por Carlos Velásquez. Véase Cuadernos, 1944, p. 9.

11 Con respecto al arte rupestre peruano "los motivos grabados corresponden, por una parte, a seres sobrenaturales antropomorfos... en actitudes diversas: con los brazos alzados o cruzados...se reconoce también la representación de la trilogía animal clásica de la iconografía formativa: felinos-aves rapaces-serpientes...existen igualmente unos escasos signos, tal como el ojo excéntrico, la boca dentada y la cruz". (Guffroy, 2009, p.13).

12 Gálvez, 1968, p. 32.

13 C.L., 1968, p. 18.

14 G.D.R., 1968, p. 25. 
15 J.A., 1968, p. 23.

16 IV Salón, 1968, p. 25.

17 Abren, 1968, p. 4.

18 Ñ.C.L., 1966, p. 18.

19 Hostnig (2018), al analizar el arte milenario en la Cordillera de Carabaya, Puno, ofrece una clasificación de dicho arte según las formas zoomorfas, antropomorfas, escenas de caza y ornamentales tipo tejido. La trama de la obra de Camino Sánchez sugiere una intención ornamental rupestre.

20 Gabriela Tineo, directora de la Galería Delbarrio, viene realizando una investigación en la cual propone con sólidos argumentos que las iniciales del artista forman parte de un patrón que se repite permanentemente en las xilografías dedicadas al arte precolombino.

21 La siguiente noticia manifiesta el interés de nuestro artista por la astronomía, la cual también es incorporada en algunas de sus obras: "Un original Globo Lunar ha sido elaborado por alumnos de la Gran Unidad Escolar "Ricardo Bentín" del Rímac, bajo la dirección del profesor de Artes Plásticas Julio Camino Sánchez... Además se ha señalado en forma ostensible el punto en el que los expedicionarios del Apolo 11 bajaron en el módulo, hollando por primera vez pisadas terrestres el misterioso planeta selenita" (Elaboran, 1970, p. 6).

22 Pinilla, 2005, p. a12.

23 Destacamos que la principal diferencia entre ideología y cosmovisión se encuentra en su carácter de cerrazón o apertura a la realidad. Una ideología es una interpretación preconcebida del mundo desde la cual se acomoda la realidad, descartando todo lo que no es coherente con el sistema de ideas planteado. La cosmovisión es una concepción integral del mundo construida a partir del ordenamiento de la experiencia personal y de la tradición cultural recibida. Mientras la ideología intenta explicarlo todo, la cosmovisión se ocupa del sentido de las cosas, dejando temas abiertos.

\section{Referencias}

Ávila, N. (2010). El Arte Cósmico de Tamayo. México D.F.: Editorial Praxis.

Campana, C. (1995). Arte Chavin, análisis estructural de formas e imágenes. Lima: Universidad Nacional Federico Villarreal.

Castrillón, A. (2002). De Abstracciones. Informalismos y otras historias. Lima: ICPNA.

Cirlot, E. (1965). El Espiritu del Arte Abstracto. Barcelona. Editorial Labor.

Fernández, A. (1995). Grabadores en el Perú. Bosquejo histórico 1574-1950. Lima: José Abel Fernández.

Fernández, J. (2003). Diccionario de Estética de las Artes Plásticas. Buenos Aires: Condorhuasi.

Guffroy, J. (2009). Imágenes y Paisajes Rupestres del Perú. Lima: Universidad de San Martín de Porres.

Hostnig, R. (2018). Macusani y Corani, repositorios del Arte Rupestre Milenario en la Cordillera de Carabaya, Puno-Perú. Recuperado el 2 de mayo de 2018 de ht- 
tps://www.rupestreweb.info/macusani.html.

Kogan, J. (1986). Filosofía de la Imaginación. Función de la imaginación en el arte, la religión y la filosofía. Buenos Aires: Paidos.

Majluf, N. \& Wuffarden, L. (1999). Elena Izcue, el arte precolombino en la vida moderna. Lima: MALI.

Miró Quezada, L. (1966). Arte en Debate. Lima: FAUA; Universidad Nacional de Ingeniería.

Morris, R. (1981). Texto curatorial de la muestra Raices Prehispánicas en la Plástica Peruana. Lima: ICPNA.

Munive, M. (2015). Carlos Bernasconi, antología xilográfica 1953-2015. Lima: ICPNA.

-. (2018). Texto curatorial de la exposición Notas de Campo, Proyecto Rupestre Contemporáneo. Arequipa: ICPNA.

Ruiz, J. (2004). Introducción a la iconografía andina 1. Lima. IDESI.

Ugarte Eléspuru J.M. (1963). Presentación de la carpeta de grabado de Julio Camino Sánchez, "Arte del Perü". Lima.

Ugarte Eléspuru J.M. (1965). Presentación de la carpeta de grabado de Julio Camino Sánchez, "El Mate Burilado". Lima.

Ugarte, J. (1979). Presentación de la muestra "Paisajes Costeños". Lima: Galería Enrique Camino Brent.

Villegas F. (s/f.). Acuarelas. El proyecto inédito de José Sabogal y su escuela. La Colección del Instituto de Arte Peruano (1931-1973). Manuscrito inédito.

Villegas F. (2017). La importancia del arte y el diseño del Perú Antiguo en el imaginario de los artistas peruanos del siglo XX: las propuestas artísticas de Elena Izcue y José Sabogal. En Investigaciones en Arte y Diseño. Lima: Pontificia Universidad Católica del Perú. Facultad de Arte y Diseño, 33-57

Artículos Periodísticos

Abren el IV Salón Nacional de Grabado (1968). Correo Magazine, suplemento de Correo, 25 de setiembre, 4 .

C.L. (1968). Crítica de Arte. La Prensa, 19 de marzo, 8.

Cuadernos de Dibujo (1944). Diario Universal, 17 de setiembre, 9.

Elaboran 'Globo Lunar' (1970). La Crónica, 1 de enero, 6.

Gálvez, E. (1968). ¡De tal palo, tal grabado! 7 Días del Perú y del Mundo (536), suplemento de La Prensa, 29 de setiembre, 32.

Exposición de Arte Popular Peruano abrieron en Insula (1964). El Comercio, 27 de agosto, 3 . 
G.D.R. (1968). Demostración de Grabado. Oiga (262), 25.

J.A. (1968). "Tacos" como obra de arte. Grabados de J. Camino S. El Comercio, 26 de marzo, 23.

Las facetas de Julio Camino Sánchez (2005). La República, 4 de agosto, 7.

Moll, E. (1968). Las xilografías de Camino Sánchez. La Crónica, 7 de octubre, 11.

Ñ.C.L. (1966). Crítica de Arte, Camino Sánchez. La Prensa, 21 de abril, 18.

Pinilla, J. (2005). Pintar después de los 90. El Comercio, 17 de agosto, 12.

IV Salón de Grabado (1968). Última Hora, 25 de setiembre, 27. 
